\title{
Risk Evaluation in Auto Spare Parts Transport Based on the AHP Method
}

\author{
Rong Zeng ${ }^{1}$ and Chang $\mathrm{Xu}^{2}$ \\ ${ }^{1}$ Wuhan Huaxia University of Technology, Wuhan, China \\ ${ }^{2}$ Wuhan University of Technology, Wuhan, China
}

\begin{abstract}
By way of example we analyze various risks exist in auto spare parts transportation, building engineering logistics risk evaluation index system of auto spare parts transportation, and the introduction of AHP, be more rational auto spare parts transportation risk assessment methods, strengthen risk management auto spare parts auto spare parts transportation to provide a reference for other engineering logistics auto spare parts transportation.
\end{abstract}

\section{Introduction}

Auto spare parts primarily relates to transport objects of transport, handling, packaging and storage, these relatively independent but closely linked aspects constitute the complete logistics process. In particular, the process object transportation risk is an objective reality, and has a dynamic variability, diversity, but also by subjective factors, so the analysis of engineering logistics risk is very important. [1].

Currently there are many research concerning logistics risk[2-3], but not a specific risk assessment system of auto spare parts transportation. Taking a highway transport precast beams Tianjin, for example, the establishment of a transport risk factor assessment model, a comprehensive evaluation of the risk presented for the segment prefabricated beams risk assessment system and risk control measures, to hedge against the risk of auto spare parts transportation auto spare parts services.

\section{AHP}

Analytic Hierarchy Process (Analytic Hierarchy Process, AHP) is home Satty American operations research in the early 1970s to make his decision analysis method for quantitative and qualitative. It policymakers thought process complex decision-making system will be modeled quantify. Application of this method, the makers of complex problems down into a number of factors and a number of levels, between the various factors pair wise comparisons and calculations, get different weights, provide the basis for selecting the best solution[4-5]. AHP method can be divided into four steps: First, analyze the relationship between the various factors in the system, create a system of hierarchical structure; then the same level of importance of various elements on a layer corresponding guidelines pair wise comparison, construct pair wise comparison judgment matrix; and then by the judgment matrix calculation is to compare elements of the guidelines should be relatively heavy weight; and finally calculate the levels of the elements of the overall target system combining weights, and sort.

\section{The establishment of auto spare parts transportation risk assessment model}




\subsection{Construction of evaluation index hierarchy Project}

logistics auto spare parts transportation is a very complex process, involving many areas of technology, management, science, etc., is also related to the relevant factors affecting the transport business, management section, etc., for the selected indicators are more in the actual process should remove duplicate factors avoid larger deviations from the actual situation. Tianjin highway below a certain precast transport for example.

\subsection{Judgment matrixt}

After the establishment of the hierarchy analysis model, the relative importance of each factor on each score given by experts. Two more things to make an accurate comprehensive judgment, is assessed by expert opinion, referring to SUTTY nine scale method, in proportion to the scale defined by the extent of importance assigned to construct the index levels of judgment matrix. To avoid errors of judgment, but also to construct judgment matrix consistency test[6-7].

Judgment matrix calculation utilizing the relative weight $W_{i}$ and each index coefficient matrix characteristic root, as follows:

(1) calculate the matrix product of all elements in each row: $M_{i}=\prod_{j=1}^{n} a_{i j}$, where $i=1,2, \ldots, n, n$ is the order of the matrix;

(2) $M_{i}$ be opened the n-th power: $\bar{W}_{i}=\sqrt[n]{M_{i}}$;

(3) $\left(\bar{W}_{1}, \bar{W}_{2}, \ldots, \bar{W}_{n}\right)^{T}$ will be normalized: $w_{i}=\frac{\bar{w}_{i}}{\sum_{j=1}^{n} \bar{w}_{j}}$;

(4) Calculate the characteristic roots: $\lambda_{\max }=\sum_{i=1}^{n} \frac{(B W)_{i}}{n W_{i}}$.

Calculate the characteristic roots level by a single sort consistency index: $C . I=\frac{\lambda_{\max }-n}{n-1}$;

Random Consistency Index is then calculated: $C . R=\frac{C . I}{R . I}$; if $C . R \leq 0.1$ that is acceptable consistency of judgment matrix, wherein the average random consistency index $R I$ is derived using a random sampling method, the value shown in Table 1.

Table 1. Average random consistency index R.I

\begin{tabular}{|l|l|l|l|l|l|l|l|l|}
\hline dimension & 1 & 2 & 3 & 4 & 5 & 6 & 7 & 8 \\
\hline R.I & 0.00 & 0.00 & 0.58 & 0.96 & 1.12 & 1.24 & 1.32 & 1.41 \\
\hline
\end{tabular}

Criterion level factors environment, operation, management, auto spare parts vehicle to the target layer $\mathrm{U}$ of total auto spare parts transpotation risk judgment matrix in Table 2-6.

Table 2. Judgement matrix of $U-U_{i}$

\begin{tabular}{|l|ccccc|l|ll|}
\hline $\boldsymbol{U}$ & $\boldsymbol{U}_{\boldsymbol{1}}$ & $\boldsymbol{U}_{\mathbf{2}}$ & $\boldsymbol{U}_{\mathbf{3}}$ & $\boldsymbol{U}_{\mathbf{4}}$ & $\mathbf{W}_{\mathbf{0}}$ & index & \\
\hline $\boldsymbol{U}_{\boldsymbol{1}}$ & 1 & $1 / 3$ & $1 / 5$ & $1 / 3$ & 3 & 0.077 & $\lambda_{\max }=4.104$ & C.I $=0.035$ \\
$\boldsymbol{U}_{\mathbf{2}}$ & 1 & $1 / 3$ & 2 & & & 0.238 & & \\
$\mathbf{U}_{\mathbf{3}}$ & 5 & 3 & 1 & 3 & 0.517 & R.I $=0.96$ & C.R $=0.036<0.1$ \\
$\mathbf{U}_{\mathbf{4}}$ & 3 & $1 / 2$ & $1 / 3$ & 1 & 0.168 & & \\
\hline
\end{tabular}

Programmer layer factor $U_{l j}$ of $U_{l}$ judgment matrix in Table 3. 
Table 3. Judgement matrix of $U_{1}-U_{1 j}$

\begin{tabular}{|c|c|c|c|c|c|}
\hline $\mathbf{U}_{1}$ & $\begin{array}{l}U_{11} \\
U_{13} \\
\end{array}$ & $U_{12}$ & $W_{1}$ & index & \\
\hline $\begin{array}{l}\mathrm{U}_{11} \\
\mathrm{U}_{12}\end{array}$ & $\begin{array}{l}1 \\
1 / 5\end{array}$ & $1 / 3$ & $\begin{array}{l}0.106 \\
0.258\end{array}$ & $\lambda_{\max }=3.04$ & C.I $=0.02$ \\
\hline $\mathbf{U}_{13}$ & $\begin{array}{l}3 \\
1 / 3 \\
5 \\
1\end{array}$ & $\begin{array}{l}1 \\
3\end{array}$ & 0.636 & $\begin{array}{l}\text { R.I }=0.58 \\
\text { C. } R=0.03<0.1\end{array}$ & \\
\hline
\end{tabular}

Table 4. Judgement matrix of $U_{2}-U_{2 j}$

\begin{tabular}{|l|lc|l|lr|}
\hline$U_{2}$ & $U_{21}$ & $U_{22}$ & $W_{i}$ & index & \\
\hline$U_{21}$ & 1 & $1 / 3$ & 0.25 & $\lambda_{\max }=2$ & C.I $=0$ \\
$U_{22}$ & 3 & 1 & 0.75 & R.I $=0$ & C.R $=0<0.1$ \\
\hline
\end{tabular}

Table 5. Judgement matrix of $U_{3}-U_{3 j}$

\begin{tabular}{|l|ccc|l|ll|}
\hline $\boldsymbol{U}_{3}$ & $\boldsymbol{U}_{31}$ & $\boldsymbol{U}_{32}$ & $\boldsymbol{U}_{33}$ & $\boldsymbol{W i}$ & index & \\
\hline $\boldsymbol{U}_{31}$ & 1 & $1 / 3$ & $1 / 5$ & 0.106 & $\lambda_{\max }$ & $=3.04$ \\
$\boldsymbol{U}_{32}$ & 3 & 1 & $1 / 3$ & 0.258 & \\
$\boldsymbol{U}_{33}$ & 5 & 3 & 1 & 0.636 & C.I $=0.02$ & \\
& & & & & R.I $=0.58$ & \\
& & & & & C.R $=0.03<0.1$ & \\
\hline
\end{tabular}

Table 6. Judgement matrix of $U_{4}-U_{4 j}$

\begin{tabular}{|l|lrr|l|ll|}
\hline $\boldsymbol{U}_{4}$ & $\boldsymbol{U}_{41}$ & $\boldsymbol{U}_{42}$ & $\boldsymbol{U}_{42}$ & $\boldsymbol{W}_{\boldsymbol{i}}$ & index & \\
\hline $\boldsymbol{U}_{41}$ & 1 & $1 / 2$ & $1 / 6$ & 0.090 & $\lambda_{\max }=3.013$ & C.I $=0.007$ \\
$\boldsymbol{U}_{42}$ & 2 & & 1 & 0.322 & & \\
$\boldsymbol{U}_{43}$ & $1 / 4$ & & & 0.588 & R.I $=0.58$ & \\
& 6 & & 4 & & C.R $=0.011<0.1$ & \\
& 1 & & & & & \\
\hline
\end{tabular}

When $\lambda_{\max }=2, C . R=0$ is exactly the same. $C R$ larger the value, the worse the consistency of judgment matrix, the matrix due to the judgment $C R$ value is less than 0.1 , it is considered that they have a satisfactory consistency.

It should be noted that in practice, the hierarchical model of the number of layers of factors and factors of pairwise comparisons between two values are not static, but according to the specific circumstances by experienced, expert judgment and strong decision.

\section{Fuzzy comprehensive evaluation}

\subsection{Identify factors set and evaluation set}

As the auto spare parts complex reality, even the experts can not give an accurate assessment can only be a vague assessment. Linguistic variables can be approximated to describe the complex phenomenon not clearly defined characteristics. Such as "risk" as a factor set "high risk, high risk, moderate risk, general risk, low risk, no risk" can be set as one of its judgment. On precast beam transported example, the judge set $V=\{$ a very high risk, high risk, general risk, low risk, low risk\}, and quantify. 
Table 7. Quantified risk grade

\begin{tabular}{|l|l|l|l|l|l|}
\hline $\begin{array}{l}\text { Risk } \\
\text { level }\end{array}$ & $\begin{array}{l}\text { Very high } \\
\text { risk }\end{array}$ & High risk & $\begin{array}{l}\text { General } \\
\text { risk }\end{array}$ & Low risk & $\begin{array}{l}\text { Very low } \\
\text { risk }\end{array}$ \\
\hline $\begin{array}{l}\text { Indicator } \\
\text { Value }\end{array}$ & $(8,10)$ & $(6,8)$ & $(4,6)$ & $(2,4)$ & $(2,0)$ \\
\hline
\end{tabular}

\subsection{Determine the fuzzy relation matrix and membership}

Fuzzy Comprehensive Evaluation of Multi-level system is to start step by step to make a more comprehensive evaluation from the lowest level up, get up to the highest level of target comprehensive evaluation results of the original problem. Here departure from the program level indicators, the first layer of each factor fuzzy comprehensive evaluation criteria, and then the target layer fuzzy comprehensive evaluation factors.

(1) The second level fuzzy comprehensive evaluation factor. Order membership $R_{i j}=\left\{r_{i j}, r_{i j 2}, \ldots r_{i j n}\right\}$, then the second level of single factor evaluation matrix:

$$
R_{i}=\left[\begin{array}{cccc}
r_{i 11} & r_{i 12} & \cdots & r_{i 1 n} \\
r_{i 21} & r_{i 22} & \cdots & r_{i 2 n} \\
& & & \\
r_{i m 1} & r_{i m 2} & \cdots & r_{i m n}
\end{array}\right] \text { factor to obtain a second level fuzzy comprehensive evaluation level is }
$$

$B_{i}^{\prime}=W_{i} \circ R_{i}=\left[b_{i 1}, \quad b_{i 2}, \cdots, b_{i 3}\right]$, where" $\circ$ "is fuzzy Operators can select the appropriate algorithm according to different situations. Assessment by the first group of 10 people on the second level of each factor single factor evaluation factors, such as the factors set $U_{l}=$ \{environment, weather, geology $\}$ three factors of risk evaluation, assessment team voting results are shown in Table 8.

Table 8. $U_{11}$ risk evaluation by expert

\begin{tabular}{|c|r|r|l|r|l|}
\hline & $\begin{array}{c}\text { Very } \\
\text { high } \\
\text { risk }\end{array}$ & $\begin{array}{l}\text { High } \\
\text { risk }\end{array}$ & $\begin{array}{l}\text { General } \\
\text { risk }\end{array}$ & $\begin{array}{l}\text { Low } \\
\text { risk }\end{array}$ & $\begin{array}{l}\text { Very } \\
\text { low risk }\end{array}$ \\
\hline $\begin{array}{c}U_{I I} \text { envir- } \\
\text { onment }\end{array}$ & 0 & 0 & 0 & 3 & 7 \\
\hline$U_{12}$ Weather & 0 & 0 & 0 & 5 & 5 \\
\hline$U_{13}$ geology & 0 & 0 & 0 & 5 & 5 \\
\hline
\end{tabular}

\subsection{Calculate the weight of each layer combining weights}

The right combination of computing the weight of each layer are shown in Table 9, and consistency checking.

Table 9. The total sort Computation sheet of $U$

\begin{tabular}{|l|llll|l|}
\hline$U$ & $U_{1}$ & $U_{2}$ & $U_{3}$ & $U_{4}$ & weight \\
& $\mathbf{0 . 0 7 7}$ & $\mathbf{0 . 2 3 8}$ & $\mathbf{0 . 5 1 7}$ & $\mathbf{0 . 1 6 8}$ & \\
\hline$U_{11}$ & 0.106 & & & & 0.008 \\
$U_{12}$ & 0.258 & & & & 0.020 \\
$U_{13}$ & 0.636 & & & 0.049 \\
$U_{21}$ & & 0.25 & & 0.060 \\
$U_{22}$ & & 0.75 & & 0.179 \\
\hline
\end{tabular}




\begin{tabular}{|l|ll|l|}
\hline $\boldsymbol{U}_{31}$ & 0.106 & & 0.055 \\
$\boldsymbol{U}_{32}$ & 0.258 & & 0.133 \\
$\boldsymbol{U}_{33}$ & 0.636 & & 0.329 \\
$\boldsymbol{U}_{41}$ & & 0.090 & 0.015 \\
$\boldsymbol{U}_{42}$ & & 0.322 & 0.054 \\
$\boldsymbol{U}_{43}$ & & 0.588 & 0.099 \\
\hline
\end{tabular}

$C . I=\sum_{i=1}^{n} W_{i}^{B}(C . I)^{T}=(0.077,0.238,0.517,0.168)(0.02,0,0.02,0.007) \mathrm{T}=0.0131$

$R . I=\sum_{i=1}^{n} W_{i}^{B}(R . I)^{T}=(0.077,0.238,0.517,0.168)(0.58,0,0.58,0.58)=0.4420$

$C . R=\sum_{i=1}^{n} W_{i}^{B}(C . R)^{T}=0.03<0.1$,indicating that meet the conformance requirements.

\subsection{Ealuation}

As can be seen from Table 7 that $U_{2}$ and $U_{3}$ manage operational impact on auto spare parts transportation safety prefabricated beams relatively large, and relatively small impact on the environment. $U_{33}$ level in the second stage security personnel awareness maximum impact on transport. In the process of precast auto spare parts transportation to ensure safe and smooth it can reach the destination, the risk must be controlled from the management and operation of two aspects, in particular, to strengthen the security personnel education.

\section{Conclusion}

Step article using AHP to Tianjin, a highway auto spare parts transportation precast beams, for example, to build a hierarchy of risk, combined with expert opinion to determine the various levels of judgment matrix, right by the formula to calculate the factors of weight, and consistency inspection, forming a total weight sort table, laid the foundation for further evaluation of the risk of auto spare parts transportation. However, because data collection is limited, this risk hierarchy needs to be further improved.

\section{Acknowledgments}

The authors thank the reviewers who gave a through and careful reading to the original manuscript. Their comments are greatly appreciated and have help to improve the quality of this paper. This work is supported in part by the Scientific Research Plan of Hubei Province (No.B2016408).

\section{References}

1. Wang, Ailing. Fuzzy risk assessment of construction project contractors based on entropy-weight coefficient method. Electric Technology and Civil Engineering (ICETCE), 2011 International Conference on IEEE, (2011).

2. Markowski A S, Mannan M S. Fuzzy risk matrix Journal of Hazardous Materials, (2008).

3. Li, Chaoyang, C. Ye, and Y. Shen. Risk Assessment of Subway Pit Construction Based on Fuzzy Comprehensive Evaluation. Chinese Journal of Underground Space \& Engineering 10 (2014).

4. Erkut, Erhan, and A. Ingolfsson. Transport Risk Models for Hazardous Materials: Revisited. Social Science Electronic Publishing

5. ERKUT Erhan, and INGOLFSSON Armann. Transport risk models for hazardous materials: revisited. Operations Research Letters (2005). 
6. Verma, Manish. Railauto spare parts transpotationation of dangerous goods: A conditional exposure approach to minimize transport risk. Transportation Research Part C Emerging Technologies 19 (2011).

7. Chapman, Rebekah L., et al. The impact of school connectedness on violent behavior, transport risk-taking behavior, and associated injuries in adolescence. Journal of School Psychology 49 (2011).

8. Paulo Sérgio, Lucas Da Silva, E. D. A. Vania, and R. Maria Eunice. Assessing outcome in interhospital infant transport: the transport risk index of physiologic stability score at admission. American Journal of Perinatology 29(2012) 